\title{
Estudo Comparativo entre a Cardiotocografia Anteparto e o Doppler em Fetos Considerados Clinicamente Normais
}

\author{
Autor:Mauro da Silva Casanvoa \\ Orientador: Prof. Dr. Francisco Mauad Filho
}

Dissertação de Mestrado apresentada ao Departamento de Ginecologia e Obstetrícia da Faculdade de Medicina de Ribeirão Preto (Área de concentração: Tocoginecologia) - USP, em 25 de junho de 2001.

Procurou-se avaliar fetos considerados normais, com o uso do efeito Doppler, estudando-se os índices de resistência e pulsatilidade dos vasos: artéria cerebral média, artéria umbilical, aorta abdominal e ducto venoso, bem como as variáveis cardiotocográficas anteparto basal, como o nível da freqüência cardíaca fetal (FCF), variabilidade, amplitude e duração da resposta ao estímulo sonoro. Foram estudados dois grupos de pacientes, divididas em grupo I, composto de 32 gestantes com idade gestacional entre 26 e 31 semanas e 6 dias e grupo II, constituído de 32 gestantes com idade gestacional acima de 32 semanas. Todas as gestantes encontravam-se clinicamente normais e foram atendidas no ambulatório de pré-natal normal do Hospital das Clínicas da Faculdade de Medicina de Ribeirão Preto, da Universidade de São Paulo (HCFMRPUSP) e assistidas na Escola de Ultra-Sonografia e Reciclagem Médica de Ribeirão Preto (EURP). Os resultados foram divididos de acordo com a caracterização das gestantes, os resultados descritivos e os resultados analíticos. Todas as variáveis dos resultados descritivos e analíticos foram primeiramente avaliadas com os testes de normalidade, Shapiro \& Wilk, cujos resultados levaram à opção por métodos não paramétricos, para a análise dos dados. Para fazer as comparações entre os grupos I e II, com cada variáveis cardiotocográficas e os índices de resistência e pulsatilidade através do Doppler pela Ultra-Sonografia, fo- ram analisadas pelo coeficiente de Spearman e o teste correspondente. O nivel de significância considerado foi de $\alpha=0,05$. As variáveis cardiotocográficas mostraram diferença estatística significante entre os grupos I e II, quanto à FCF, amplitude e tempo. Conclui-se que o nível de FCF é maior em fetos com menos tempo de gestação e que a amplitude de elevação da FCF, após o estímulo sonoro e o tempo para voltar ao normal, são maiores nos fetos com mais tempo de gestação. Com relação às variáveis do efeito Doppler, os grupos I e II mostraram diferenças estatisticamente significantes quanto aos índices de resistência da artéria cerebral média e da artéria umbilical e índice de pulsatilidade da artéria cerebral média, artéria umbilical e do ducto venoso. Conclui-se que o indices são maiores em fetos com menos tempo de gestação. Quando correlacionou-se as variáveis cardiotocográficas com as variáveis do efeito Doppler, não foi encontrada diferença significativa entre essas variáveis, pois trata-se de gestantes e fetos sem patologias. O trabalho permitiu compreender o comportamento das variáveis biofisicas, de fetos considerados normais, em periodos gestacionais diferentes, possibilitando melhores estudos frente a fetos com hipoxemia isquêmica, metabólica e hematogênica.

Palavras-chave: Dopplervelocimetria. Carditotocografia anteparto. Gravidez normal.

\section{Avaliação do Uso do Condom Feminino em Mulheres Vivendo com o HIV}

Autor: Jarbas Magalhães

Orientadora: Profa. Dra. Eliana Amaral

Tese de Doutorado apresentada à Área de Tocoginecologia da Unicamp, para obtenção do Título de Doutor em Ginecologia, em 18 de setembro 2001.

Para avaliar a aceitabilidade, a adesão e a experiência com o uso de condom feminino entre mulheres contaminadas pelo HIV, do Ambulatório de Infecções Genitais-II da UNICAMP e Centro Corsini, desenvolveu-se um estudo descritivo prospectivo. As $76 \mathrm{mu}-$ lheres que aceitaram participar responderam a uma entrevista de triagem, quando receberam um calendário para anotação das relações sexuais e uso de condom masculino. Após 30 dias, compareceram à visita de treinamento para colocação do condom feminino em modelo pélvico, trazendo o diário de relações sexuais deste ciclo, considerado controle. Foram entrevistadas atra- vés de questionário estruturado após 30, 60 e 90 dias, trazendo sempre o diário onde deveriam ser registradas as relações sexuais, com uso ou não, do condom feminino ou masculino. A análise estatística foi realizada utilizando-se os testes de Qui-Quadrado, Exato de Fisher, McNemar e Friedman para amostras emparelhadas. A população estudada foi predominantemente constituída de mulheres jovens, de baixa escolaridade e dois terços delas moravam com o parceiro. Observaram-se altas taxas de uso (87\%), continuidade $(78 \%)$ e aceitabilidade $(68 \%)$ do condom feminino, ao longo de 90 dias de estudo. O uso de condom feminino, em tor- 
no de metade das relações sexuais em cada periodo de estudo, permaneceu estável nos 90 dias. Houve uma expressiva diminuição da proporção média das relações sexuais desprotegidas (de $14 \%$ para $6 \%$ ), sem o uso de condons masculinos ou femininos, aos 90 dias. As dificuldades no manuseio do condom feminino, observadas no início, foram superadas com a continuidade do uso. Entre as vantagens mais citadas se destacaram: o poder de decisão de uso pertencer à mulher, a dupla proteção contra gravidez e DST/HIV e não depender do homem para usar. As desvantagens mais referidas incluíram ser caro, feio e fazer barulho, sendo que a última praticamente deixou de ser citada no final do estudo. Os casais soro-discordantes tive- ram maior proporção de relações protegidas que os casais soro-concordantes, porém a diferença não foi significativa. As mulheres que relataram uso prévio de condom masculino por seus parceiros, em todas as relações sexuais, apresentaram um número significantemente maior de relações protegidas. Concluindo, a oferta do condom feminino acompanhada de aconselhamento apropriado foi capaz de reduzir as relações sexuais desprotegidas entre mulheres infectadas pelo HIV, que se mostraram motivadas e receptivas a este método, dele obtendo importante beneficio.

Palavras-chave: AIDS. Doenças sexualmente transmissiveis. Contracepção. Método de barreira. Condom.

\section{RBCO $24(2): 138,2002$}

\section{Pesquisa de Óxido Nitrico no Fluido Peritoneal e no Soro de Pacientes com Endometriose}

Autora: Rogéria Teixeira Coelho

Orientadora: Profa. Dra. Maria do Carmo Borges de Souza

Dissertação de Mestrado apresentada ao Instituto de Ginecologia da Universidade Federal do Rio de Janeiro, em 11 de dezembro de 2000.

O Óxido Nítrico (NO) é um gás liberado a partir da reação de oxigenação do aminoácido L-arginina pelas Óxido Nítrico Sintases (NOS), em pequenas quantidades em condições fisiológicas e, em maiores quantidades, em condições patológicas, como no processo inflamatório e choque séptico. O NO foi inicialmente chamado de EDRF (Fator de Relaxamento Derivado do Endotélio), está presente nos processos de vasodilatação endotelial intensa, como ocorre no peritôneo de pacientes com endometriose. Com intuito de investigar a participação do NO no processo inflamatório e na vasodilatação que estão presentes na endometriose, foi pesquisada a presença desta substância no fluido peritoneal e no soro de pacientes submetidas à videolaparoscopia. Este trabalho de pesquisa foi realizado com 65 pacientes submetidas à videolaparoscopia no período de março de 1999 a agosto de 2000; durante o exame foi realizada a colheita do fluido peritoneal (fundo-de-saco de Douglas) e do soro das mesmas, para dosagem de NO através da técnica de conversão de nitrato à nitrito e quantificada por espectrofotometria, no Laboratório de Farmacologia da Inflamação e do
Óxido Nítrico da Universidade Federal do Rio de Janeiro. A análise estatística aplicada através dos testes de Mann-Whitney e Qui-quadrado e a determinação de significância foi de $5 \%$ (p valor menor ou igual a $0,005)$, demonstrou diferença siginificativa nas dosagens de NO tanto no soro quanto no fluido peritoneal das pacientes com endometriose, respectivamente, $50.30 \mathrm{nM}$ no soro e $51.77 \mathrm{nM}$ no fluido, em média significativamente maior do que nas pacientes sem endometriose. Os dados sugerem que as alterações inflamatórias e a vasodilatação intensa presentes principalmente nos estágios iniciais da endometriose, podem estar relacionados com a liberação de radicais livres e mediadores químicos específicos. A conclusão do trabalho foi que a dosagem do NO no soro e no fluido peritoneal das pacientes com ou sem endometriose foi significativamente maior naquelas com endometriose.

Palavras-chave: Óxido nítrico, efeitos adversos. Peritôneo, efeito de drogas. Endometriose, etiologia. Doença crônica. 